OPEN ACCESS

Citation: S. Jantarat, S. Jumrusthanasan, S. Kaewsri, P. Supanuam, A. Tanomtong (2021) Firstreportof karyological analysis and heteromorphic nucleolar organizer region of Black Surgeonfish (Acanthurus gahhm, Acanthuridae) in Thailand. Caryologia 74(1): 83-88. doi: 10.36253/caryologia-853

Received: February 06, 2020

Accepted: April 26, 2021

Published: July 20, 2021

Copyright: (c) 2021 S. Jantarat, S. Jumrusthanasan, S. Kaewsri, P. Supanuam, A. Tanomtong. This is an open access, peer-reviewed article published by Firenze University Press (http://www.fupress.com/caryologia) and distributed under the terms of the Creative Commons Attribution License, which permits unrestricted use, distribution, and reproduction in any medium, provided the original author and source are credited.

Data Availability Statement: All relevant data are within the paper and its Supporting Information files.

Competing Interests: The Author(s) declare(s) no conflict of interest.

\section{First report of karyological analysis and heteromorphic nucleolar organizer region of Black Surgeonfish (Acanthurus gahhm, Acanthuridae) in Thailand}

\author{
Sitthisak Jantarat ${ }^{1}$, Sarun Jumrusthanasan ${ }^{2}$, Sarawut Kaewsri ${ }^{2}$, \\ Praween Supanuam ${ }^{3, *}$, Alongklod Tanomtong ${ }^{4}$ \\ ${ }^{1}$ Program of Biology, Department of Science, Faculty of Science and Technology, Prince of \\ Songkla University, Pattani Campus, Thailand \\ ${ }^{2}$ Biology Program, Faculty of Science, Buriram Rajabhat University, Buriram, Thailand \\ ${ }^{3}$ Biology Program, Faculty of Science, Ubon Ratchathani Rajabhat University, Ubon Rat- \\ chathani, Thailand \\ ${ }^{4}$ Department of Biology, Faculty of Science, Khon Kaen University, Khon Kaen, Thailand \\ ${ }^{*}$ Corresponding author. E-mail: supanuam@hotmail.com
}

\begin{abstract}
This research was the first report on karyological analysis and heteromorphic nucleolar organizer region of black surgeonfish (Acanthurus gahhm, Acanthuridae) in Thailand. The 10 male and 10 female specimens were collected from Phuket Marine Biological Center, and Phang Nga Coastal Research and Development Center, Andaman Sea, Thailand. Mitotic chromosomes were directly prepared from gill and kidney tissues. The chromosomes were stained by conventional Giemsa staining and Ag-NOR banding techniques. Results showed that the diploid chromosomes number of A. gah$h m$ was $2 \mathrm{n}=48$, the fundamental numbers (NF) was 54 in both male and female. The karyotype consist of 6 large acrocentric, 20 large telocentric, 18 medium telocentric and 4 small telocentric chromosomes. None of strange size chromosomes related to sex was found. The heteromorphic nucleolar organizer regions (NORs) were observed on telomeric short arm of first acrocentric which can defined as 1alb. There is NOR in 1a and not in $1 \mathrm{~b}$. The karyotype formula of black surgeon fish was as follows: 2n (48) = $\mathrm{L}_{6}^{\mathrm{a}}+\mathrm{L}_{20}^{\mathrm{t}}+\mathrm{M}_{18}^{\mathrm{t}}+\mathrm{S}_{4}^{\mathrm{t}}$
\end{abstract}

Keywords: Acanthurus gahhm, chromosome, karyotype, NORs.

\title{
INTRODUCTION
}

Worldwide there are an estimated 24,000 fish species recorded, Thailand is one of the species diversity centers of the world. There are more than 13,000 and 4,000 species of fishes that live in sea and coralline, respectively (Tamrongnawasawad et al. 2004). Marine fishes are especially important as they provide a high quality source of protein and other nutrients, economically and ecological important, moreover, some species are bioindicator 
(Ohno 1970; Le Grande and Fitzsimons 1988; Affonso et al. 2014).

The Acanthuridae are the family of surgeonfishes, tangs, and unicornfishes. They are well known as ornamental fish. This family includes about 82 extant species in 6 genera, namely Acanthurus, Ctenochaetus, Zebrasoma, Paracanthurus, Prionurus and Naso. For the important character of the family, they have a colorful body. They also have a pair of dangerously precaudal spines. The genus Acanthurus has 40 species in worldwide that found in the Atlantic, Indian and Pacific Ocean. They are found in tropical oceans, especially near coral reefs, with most species in the Indo-Pacific but a few are found in the Atlantic Ocean (Monkolprasit et al. 1997; Allen et al. 2012).

Acanthurus gahhm or black surgeonfish is a demersal fish. It lives on reefs and in lagoons and other sandy areas up to 40 meters deep. This species is omnivorous, feeding on algae, zooplankton and other small invertebrates, and detritus. It is active during the day and may swim in groups or remain solitary. It is endemic to the Indian Ocean. This species is kept in aquaria and harvested for food. This fish reaches up to 50 centimeters in length. It is oval in shape and laterally compressed. The caudal fin has a crescent shape. The mouth is small and pointed. The body is black to dark brown, with a white ring around the base of the tail and a yellow stripe around the eyes. The pectoral fins are tipped with yellow (Figure 1). The black surgeonfish are one of the most colorful and economically important fish (Carpenter and Niem 2001; Allen et al. 2012).

Previous cytogenetic studies of the genus Acanthurus stated that their members are only four species, namely A. coeruleus, A. bahianus, A. chirergus and A. triostegus (Arai and Inoue 1976; Ojima and Yamamoto 1990; Galetti et al 2006; Arai 2011; Affonso et al. 2014). The two species, A. coeruleus from Brazil and A. triostegus from Japan show $2 \mathrm{n}=48$. The other species from Brazil show the diploid chromosome numbers of 36 and 34 for $A$. bahianus and A. chirurgus, respectively. Nucleolar organizer region (NOR) of the species in this family has never been reported. The present study aimed to investigate cytogenetic characterization of the Acanthurus gahhm. We exhibit the standardized karyotype and idiogram of the species and also firstly describes the chromosomal characteristics of A. gahhm by means of Giemsa conventional staining and Ag-NOR banding techniques.

\section{MATERIALS AND METHODS}

The 10 male and 10 female specimens of black surgeonfish (Acanthurus gahhm) were collected from Phuket Marine Biological Center, and Phang Nga

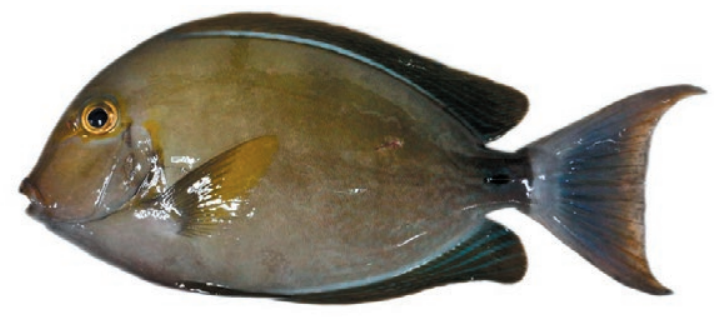

\section{black surgeonfish}

Acanthurus gahhm

$3 \mathrm{~cm}$

Figure 1. General characteristics of black surgeonfish (Acanthurus gahhm, Acanthuridae) from Phuket Marine Biological Center, and Phang Nga Coastal Research and Development Center, Andaman Sea, Thailand (Scale bars $=3 \mathrm{~cm}$ ).

Coastal Research and Development Center, Andaman Sea, Thailand. Chromosomes were directly prepared in vivo (Chen and Ebeling 1968; Nanda et al. 1995) as follows. The fishes were injected on their abdominal cavity with $0.05 \%$ colchicine for $1.0 \mathrm{ml} / 100 \mathrm{~g}$ body weight, then leaved for one hour. Chromosome preparation containing gill and kidney tissues were conducted by the colchicine-hypotonic-fixation-air drying technique. The tissues were finely chopped by scissors. The metaphase cell was three times centrifuged at $1,250 \mathrm{rpm}$ for $10 \mathrm{~min}-$ utes until the white sediment cells were precipitated. The chromosomes were stained with $20 \%$ Giemsa's for 30 minutes and identified for NORs by Ag-NOR staining according to Howell and Black (1980) and Verma and Babu (1995). Chromosomal checks were performed on mitotic metaphase cells under light microscope.

The twenty cells of each male and female appeared with clearly observable and well-spread chromosomes were selected and photographed. The length of short arm chromosome (Ls) and the length of long arm chromosome (Ll) were measured to calculate the length of total arm chromosome $(\mathrm{LT}, \mathrm{LT}=\mathrm{Ls}+\mathrm{Ll})$. In addition, the relative length (RL), centromeric index (CI), and total arm chromosome (LT) were calculated to classify the type and size of chromosomes based on Turpin and Lejeune (1965) and Chaiyasut (1989). All described parameters were used in karyotyping and idiograming according to Tanomtong et al. (2019). For the karyotype formula determination, the chromosomes were classified by size regarding to the symbol "L, M and S" as the representative of large, medium and small chromosomes, respectively. In the same way, the chromosomes were classified by type regarding to the symbol " $m$, sm, a and $t$ " as the 
representative of metacentric, submetacentric, acrocentric and telocentric chromosomes, respectively. The fundamental number (NF) is assigned a value of two for the metacentric, submetacentric and acrocentric chromosomes; however, it is assigned equal to one for the telocentric chromosome.

\section{RESULTS AND DISCUSSION}

This is the first karyological analysis of the Acanthurus gahhm. The results showed that the diploid chromosome number was $2 n=48$ and the fundamental numbers (NF) were 54 for both male and female (Figure 2). Up to the present, there are only two publications on cytogenetics of the family Acanthuridae. Affonso et al. (2001) conducted the study on cytogenetics of three species of the family Acanthuridae, namely Acanthurus coeruleus, A. bahianus and A. chirergus in Brazil. They showed the diploid chromosome number of 48 and the fundamental number (NF) of 52 for A. coeruleus. However, they demonstrated the low diploid chromosome numbers $(2 n)$ of 36 and 34 and the fundamental numbers (NF) of 52 and 50 for $A$. bahianus and A. chirergus, respectively. Arai and Inoue (1976) revealed an establishment of chromosome analysis of $A$. triostegus which were obtained from
Yakushima, Japan. The karyotype showed $2 \mathrm{n}=48$ and $\mathrm{NF}=48$, like the ancestral perciform karyotype.

The present karyotype of A. gahhm consist of 6 large acrocentric, 20 large telocentric, 18 medium telocentric and 4 small telocentric chromosomes. The twenty metaphase cells of each male and female were measured for Ls, Ll, LT, CI, RL, SD, chromosome sizes and types were showed on Table 1 . None of the strange in size of chromosome related to sex was observed. The A. gahhm has 6 bi-arm and 42 uni-arm chromosomes. The modal karyotype of ancestral Perciformes fish possessing $2 \mathrm{n}=48$, $\mathrm{NF}=48$ and composed all uni-arm chromosomes. The karyotype of $A$. gahhm indicates that although it has been revealing a model diploid chromosome number of $2 \mathrm{n}=48$, the karyotypes different from the ancestral Perciformes pattern have been detected in these studies, indicating Pericentric inversion or/ and Robertsonian rearrangements as the preferential process in some groups. The karyotype of $A$. gahhm is quite similar to the A. coeluleus karyotype. The rearrangement mechanism involves to pericentric inversions of 3 uni-arm to 3 bi-arm chromosome pairs from the ancestor. (Affonso et al. 2014).

The most species of family Acanthuridae show the typical perciform karyotype, $2 \mathrm{n}=48, \mathrm{NF}=48$, namely A. triostegus, Ctenochaetus striatus and Prionurus scalprum. The few species show diploid decreasing cause
A
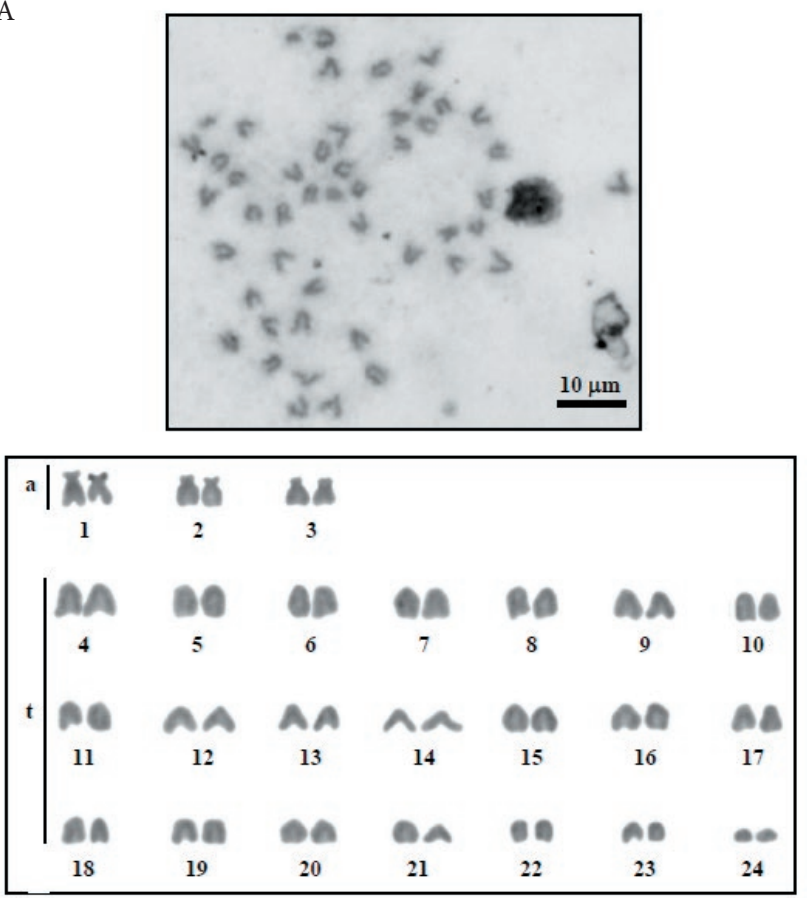
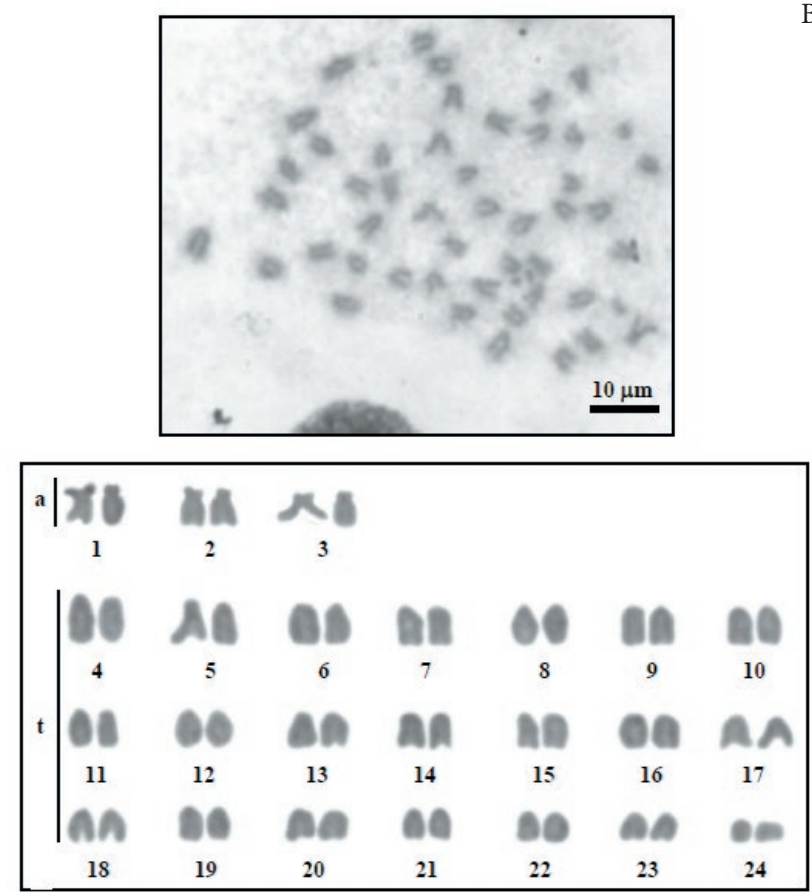

Figure 2. Metaphase plates and standardized karyotypes of male (A) and female (B) black surgeonfish, Acanthurus gahhm, $2 \mathrm{n}=48$ by conventional staining (Scale bars $=10 \mu \mathrm{m})$. 
Table 1. Mean length of the short arm chromosome (Ls), long arm chromosome (Ll), total arm chromosome (LT), centromeric index (CI), relative length (RL) and standard deviation (SD) of CI, RL from 40 karyotypes of male and female black surgeonfish (Acanthurus gahhm), $2 \mathrm{n}=48$.

\begin{tabular}{|c|c|c|c|c|c|c|c|}
\hline $\begin{array}{l}\text { Chromosome } \\
\text { pair }\end{array}$ & $\begin{array}{c}\text { Ls } \\
\text { (micron) }\end{array}$ & $\begin{array}{c}\mathrm{Ll} \\
\text { (micron) }\end{array}$ & $\begin{array}{c}\text { LT } \\
\text { (micron) }\end{array}$ & $\mathrm{RL} \pm \mathrm{SD}$ & $\mathrm{CI} \pm \mathrm{SD}$ & $\begin{array}{l}\text { Chromosome } \\
\text { size }\end{array}$ & $\begin{array}{c}\text { Chromosome } \\
\text { type }\end{array}$ \\
\hline 1 & 0.88 & 2.57 & 3.45 & $0.057 \pm 0.001$ & $0.744 \pm 0.038$ & Large & Acrocentric \\
\hline 2 & 0.76 & 2.51 & 3.27 & $0.054 \pm 0.001$ & $0.766 \pm 0.036$ & Large & Acrocentric \\
\hline 3 & 0.77 & 2.08 & 2.85 & $0.047 \pm 0.001$ & $0.729 \pm 0.019$ & Large & Acrocentric \\
\hline 4 & 0.00 & 3.37 & 3.37 & $0.055 \pm 0.003$ & $1.000 \pm 0.000$ & Large & Telocentric \\
\hline 5 & 0.00 & 3.19 & 3.19 & $0.052 \pm 0.001$ & $1.000 \pm 0.000$ & Large & Telocentric \\
\hline 6 & 0.00 & 3.13 & 3.13 & $0.051 \pm 0.002$ & $1.000 \pm 0.000$ & Large & Telocentric \\
\hline 7 & 0.00 & 3.06 & 3.06 & $0.050 \pm 0.002$ & $1.000 \pm 0.000$ & Large & Telocentric \\
\hline 8 & 0.00 & 3.01 & 3.01 & $0.049 \pm 0.002$ & $1.000 \pm 0.000$ & Large & Telocentric \\
\hline 9 & 0.00 & 2.93 & 2.93 & $0.048 \pm 0.002$ & $1.000 \pm 0.000$ & Large & Telocentric \\
\hline 10 & 0.00 & 2.66 & 2.66 & $0.043 \pm 0.000$ & $1.000 \pm 0.000$ & Large & Telocentric \\
\hline 11 & 0.00 & 2.62 & 2.62 & $0.043 \pm 0.000$ & $1.000 \pm 0.000$ & Large & Telocentric \\
\hline 12 & 0.00 & 2.55 & 2.55 & $0.042 \pm 0.001$ & $1.000 \pm 0.000$ & Large & Telocentric \\
\hline 13 & 0.00 & 2.49 & 2.49 & $0.041 \pm 0.001$ & $1.000 \pm 0.000$ & Large & Telocentric \\
\hline 14 & 0.00 & 2.41 & 2.41 & $0.039 \pm 0.001$ & $1.000 \pm 0.000$ & Medium & Telocentric \\
\hline 15 & 0.00 & 2.35 & 2.35 & $0.038 \pm 0.001$ & $1.000 \pm 0.000$ & Medium & Telocentric \\
\hline 16 & 0.00 & 2.30 & 2.30 & $0.038 \pm 0.001$ & $1.000 \pm 0.000$ & Medium & Telocentric \\
\hline 17 & 0.00 & 2.13 & 2.13 & $0.035 \pm 0.000$ & $1.000 \pm 0.000$ & Medium & Telocentric \\
\hline 18 & 0.00 & 2.05 & 2.05 & $0.033 \pm 0.000$ & $1.000 \pm 0.000$ & Medium & Telocentric \\
\hline 19 & 0.00 & 1.99 & 1.99 & $0.032 \pm 0.000$ & $1.000 \pm 0.000$ & Medium & Telocentric \\
\hline 20 & 0.00 & 1.92 & 1.92 & $0.031 \pm 0.000$ & $1.000 \pm 0.000$ & Medium & Telocentric \\
\hline 21 & 0.00 & 1.85 & 1.85 & $0.030 \pm 0.001$ & $1.000 \pm 0.000$ & Medium & Telocentric \\
\hline 22 & 0.00 & 1.76 & 1.76 & $0.029 \pm 0.001$ & $1.000 \pm 0.000$ & Medium & Telocentric \\
\hline 23 & 0.00 & 1.70 & 1.70 & $0.028 \pm 0.002$ & $1.000 \pm 0.000$ & Small & Telocentric \\
\hline 24 & 0.00 & 1.50 & 1.50 & $0.024 \pm 0.001$ & $1.000 \pm 0.000$ & Small & Telocentric \\
\hline
\end{tabular}

Table 2. Review of cytogenetic publications in the family Acanthuridae.

\begin{tabular}{|c|c|c|c|c|c|c|}
\hline Species & $2 n$ & NF & Karyotype & Ag-NOR & Locality & Reference \\
\hline Acanthurus triostegus & 48 & 48 & $48 \mathrm{t}$ & - & Japan & Arai and Inoue (1976) \\
\hline \multirow[t]{2}{*}{ A. chirurgus } & 34 & 50 & $16 \mathrm{bi}+18 \mathrm{t}$ & - & Brazil & Galetti et al. (2006) \\
\hline & 34 & - & $18 b i+16 t$ & Pair 8p & Brazil & Affonso et al. (2014) \\
\hline \multirow[t]{2}{*}{ A. bahianus } & 36 & 52 & $16 b i+20 t$ & - & Brazil & Galetti et al. (2006) \\
\hline & 36 & - & $18 \mathrm{bi}+18 \mathrm{t}$ & Pair $8 p$ & Brazil & Affonso et al. (2014) \\
\hline \multirow[t]{2}{*}{ A. coeruleus } & 48 & 52 & $4 \mathrm{bi}+44 \mathrm{t}$ & - & Brazil & Galetti et al. (2006) \\
\hline & 48 & - & $6 b i+42 t$ & Pair $2 p$ & Brazil & Affonso et al. (2014) \\
\hline A. gahhm & 48 & 54 & $6 a+42 t$ & Pair $1 \mathrm{p}$ & Thailand & Present study \\
\hline Ctenochaetus stiatus & 48 & 48 & $48 \mathrm{t}$ & - & Japan & Ojima and Yamamoto (1990) \\
\hline Prionurus scalprum & 48 & 48 & $48 \mathrm{t}$ & - & Japan & Arai and Inoue (1976) \\
\hline
\end{tabular}

Remark: $2 \mathrm{n}=$ diploid number, $\mathrm{NF}=$ fundamental number, $\mathrm{bi}=$ bi-arm chromosome, $\mathrm{t}=$ telocentric chromosome (uni-arm chromosome).

by tandem or/ and centric fusion including $A$. bahianus $(2 \mathrm{n}=36,16$ bi-arm and 20 uni-arm) and $A$. chirurgus $(2 \mathrm{n}=34,16$ bi-arm and 18 uni-arm) (Arai and Inoue 1976; Ojima and Yamamoto 1990; Galetti et al 2006;
Arai 2011; Affonso et al. 2014). The karyotype of the family Acanthuridae is shown in Table 2.

Moreover, this is the first report on localization of nucleolar organizer regions (NORs) of the Acanthurus 

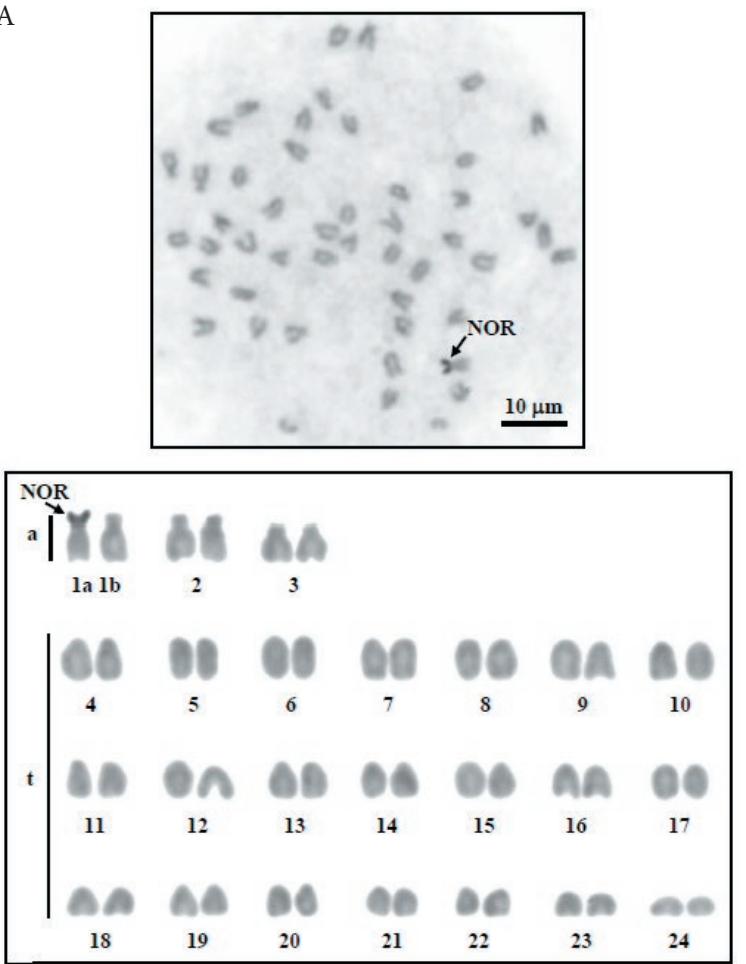

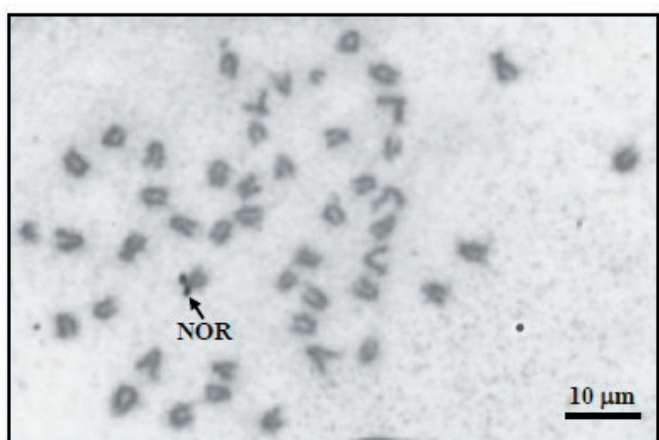

B

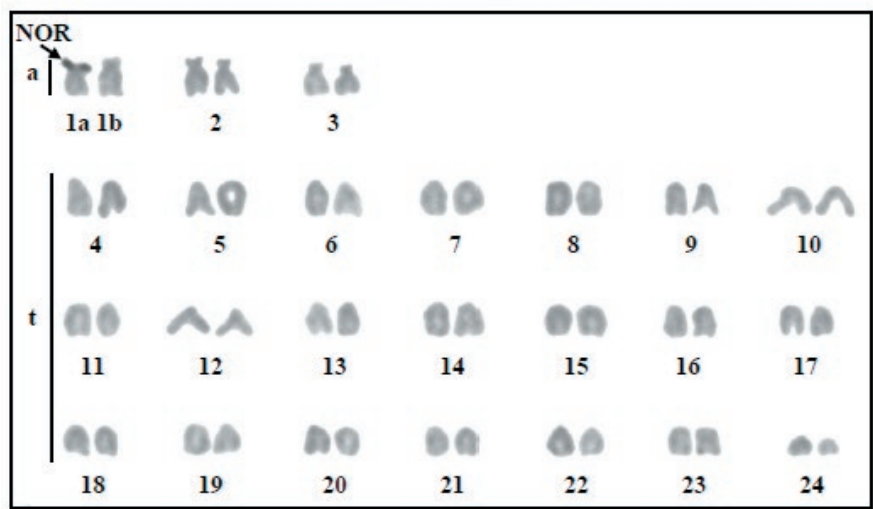

Figure 3. Metaphase plates and standardized karyotypes of male (A) and female (B) black surgeonfish, Acanthurus gahhm, 2n=48 by AgNOR banding $($ Scale bars $=10 \mu \mathrm{m})$. Chromosome pair 1 show heteromorphic NOR in 1a. Arrows indicate NORs.

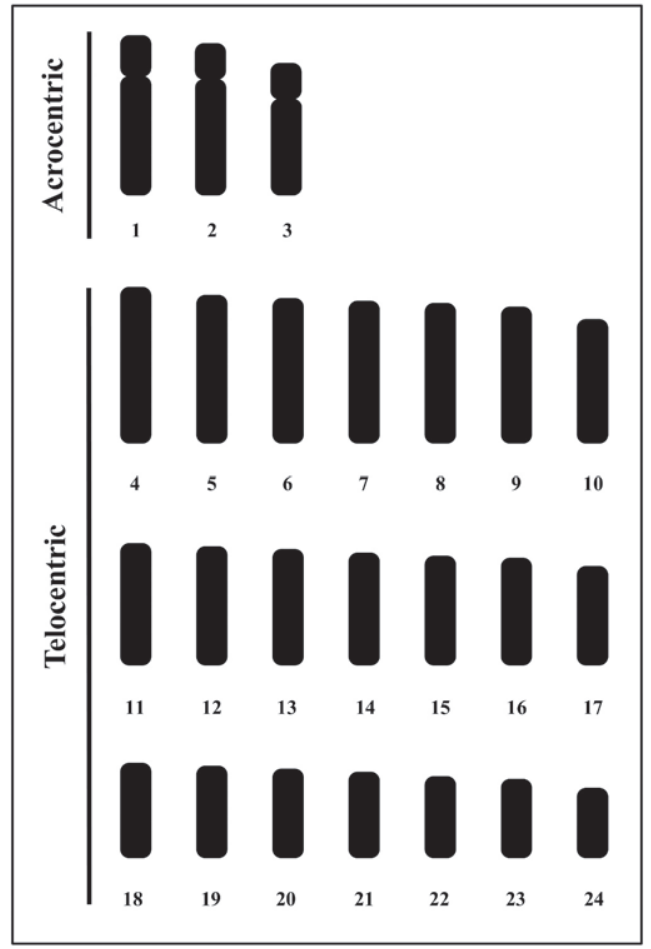

Figure 4. Standardized idiogram of black surgeonfish, Acanthurus gahhm, $2 \mathrm{n}=48$ by conventional staining.

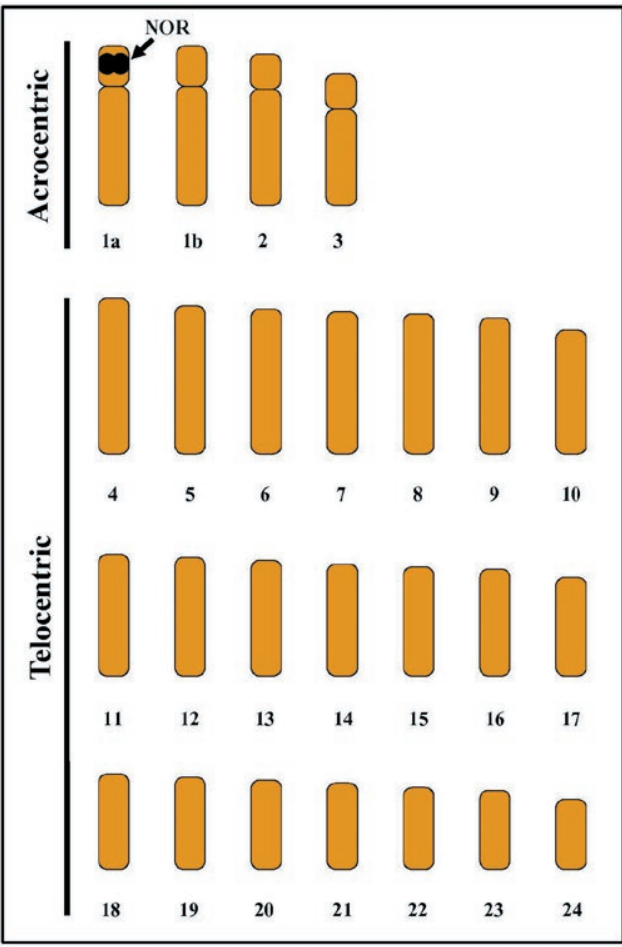

Figure 5. Standardized idiogram of black surgeonfish, Acanthurus gahhm, $2 \mathrm{n}=48$ by Ag-NOR banding. Chromosome pair 1 show heteromorphic NOR in 1a. Arrows indicate NORs. 
gahhm. One pair of the short arm of the largest chromosome 1 showed clearly observable NORs. The first record on heteromorphism of NORs in the A. gahhm (Figure 3) was also reported here. This finding indicates the presence of heteromorphic of chromosome pair 1 (lalb). NORs were found in 1a, but not in $1 \mathrm{~b}$. The three Acanthuridae species, namely A. coeluleus, A. bahianus and $A$. chirurgus show the single nucleolar organizer regions on the short arms of the largest subtelocentric pairs (Affonso et al. 2014).

The idiogram shows gradually decreasing length of the chromosomes. The largest chromosome shows two times larger than the smallest chromosome. An important karyotype trait is the presence of an asymmetrical karyotype pattern. There were only two types of chromosomes found, the acrocentric and telocentric chromosomes. The standardized conventional and Ag-NOR idiograms of Acanthurus gahhm are shown on Figure 4 and 5, respectively. The karyotype formula of black surgeonfish (Acanthurus gahhm) can be deduced as: $2 n$ (48) $=\mathrm{L}_{6}^{\mathrm{a}}+\mathrm{L}_{20}^{\mathrm{t}}+\mathrm{M}_{18}^{\mathrm{t}}+\mathrm{S}_{4}^{\mathrm{t}}$

\section{FUNDING}

This Research was financially supported by the Government Budget Grant, Prince of Songkla University, Thailand, in Fiscal Year 2017, Research Code: SAT600116S.

\section{REFERENCES}

Affonso, PRAM, Fernandas MA, Almeida JS, Molina WF. 2014. Sequential steps of chromosomal differentiation in Atlantic surgeonfishes: evolutionary inferences. The Scientific World Journal. 2014: 825703. doi: 10.1155/2014/825703.

Allen G, Steene R, Humann P, Deloach N. 2012. Reef Fish Identification: Tropical Pacific. $5^{\text {th }}$ ed. Florida: New World Publications.

Arai R. 2011. Fish karyotypes a check list. Japan: Springer.

Arai R, Inoue M. 1976. Chromosomes of seven species of Pomacentridae and two species of Acanthuridae from Japan. Bull. Natn. Sci. Mus. Tokyo, (A). 2: 73-78.

Carpenter KE, Niem VH. 2001. The living marine resources of the Western Central Pacific. Rome: Food and Agriculture Organization of the United Nations.

Chaiyasut K. 1989. Cytogenetics and cytotaxonomy of the genus Zephyranthes. Bangkok: Department of Botany, Faculty of Science, Chulalongkorn University. Thailand.
Galetti JPM, Molina WF, Affonso, PRAM, Aguilar CT. 2006. Assessing genetic diversity of Brazilian reef fishes by chromosomal and DNA markers. Genetica. 126:161-177.

Howell WM, Black DA. 1980. Controlled silver-staining of nucleolus organizer regions with a protective colloidal developer: a 1-step method. Experientia. 36:1014-1015.

Le Grande, WH, Fitzsimons JM. 1988. Chromosome numbers of some gulf coast sciaenid fishes. Copeia. 2: 491-493.

Monkolprasit S, Sontirat S, Vimollohakarn S, Songririkul T. 1997. Checklist of Fishes in Thailand. Bangkok: Office of Environmental Policy and Planning.

Ohno S. 1970. Evolution by gene duplication. New York: Springer-Verlag.

Ojima Y, Yamamoto K. 1990. Cellular DNA contents of fishes determined by flow cytometry. La Kromosomo, II. 57:1871-1888.

Phuket Marine Biological Center. 2007. A guide to Reef Fishes of the Andaman Sea, Thailand. Phuket: Phuket Marine Biological Center, Dpartment of Marine and Coastal Resources. Thai.

Tanomtong A. 2019. Cyogenetics. Bangkok; Chulalongkorn University Press. Thailand.

Turpin R, Lejeune J. 1965. Les Chromosomes Humains. Paris: Gautier-Villars. French.

Verma RS, Babu A. 1995. Human chromosomes principles and techniques. $2^{\text {nd }}$ ed. New York: McGraw-Hill Inc. 